\title{
COMMENTARY
}

\section{Ultra-protective tidal volume: how low should we go?}

\author{
Eduardo LV Costa ${ }^{* 1,2}$ and Marcelo BP Amato' \\ See related research by Retamal et al., http://ccforum.com/content/17/1/R16
}

\begin{abstract}
Applying tidal volumes of less than $6 \mathrm{~mL} / \mathrm{kg}$ might improve lung protection in patients with acute respiratory distress syndrome. In a recent article, Retamal and colleagues showed that such a reduction is feasible with conventional mechanical ventilation and leads to less tidal recruitment and overdistension without causing carbon dioxide retention or autopositive end-expiratory pressure. However, whether the compensatory increase in the respiratory rate blunts the lung protection remains unestablished.
\end{abstract}

Further reducing tidal volumes beyond the standard $6 \mathrm{~mL} / \mathrm{kg}$ is an appealing goal in patients with acute respiratory distress syndrome (ARDS) [1]. Such reduction could decrease the tidal stretch imposed on the lung, potentially attenuating further the ventilator-induced lung injury [2]. In fact, tidal volumes of less than $6.5 \mathrm{~mL} /$ $\mathrm{kg}$ and as low as $4 \mathrm{~mL} / \mathrm{kg}$ were recently associated with increased survival in patients with ARDS [3]. One of the main obstacles to such a strategy is the potential for carbon dioxide $\left(\mathrm{CO}_{2}\right)$ retention and severe acidosis. To avoid this, specialized techniques, such as high-frequency oscillatory ventilation and extracorporeal $\mathrm{CO}_{2}$ removal, have been previously tested with mixed results [4-6].

In the previous issue of Critical Care, Retamal and colleagues proposed that lower tidal volumes could be used with conventional positive-pressure ventilation without leading to $\mathrm{CO}_{2}$ retention [1]. A reduction in tidal volume from 6 to $4 \mathrm{~mL} / \mathrm{kg}$ was feasible with a decrease in the instrumental dead space and an increase in the respiratory rate. In patients with ARDS, the dead space is

\footnotetext{
*Correspondence: eduardoleitecosta@gmail.com

'Cardio-Pulmonary Department, Pulmonary Division, Hospital das Clínicas, University of São Paulo, Av. Dr. Arnaldo 455, sala 2144 (2nd floor), São Paulo, SP, Brazil. CEP: 01246-903

Full list of author information is available at the end of the article
}

a marker of disease severity [7]. Consequently, very low tidal volumes can be difficult to use in practice, especially in very sick patients, because the necessary increase in respiratory rate might cause significant auto-positive end-expiratory pressure (auto-PEEP). Luckily, patients with severe ARDS also tend to have low lung compliance [8], making their lungs inflate and deflate fast. Therefore, this restrictive ventilatory pattern allows the safe use of high respiratory rates without leading to significant auto-PEEP.

Retamal and colleagues [1] should be congratulated for their careful design of the ventilator protocol in the $4 \mathrm{~mL} / \mathrm{kg}$ phase, which allowed an effective $\mathrm{CO}_{2}$ elimination. The bottom line is that if one decides to use very low tidal volumes with high respiratory rates, attention to the details is invaluable. First, the removal of any dispensable dead space, including substituting an external heated humidifier by the heat-moisture exchanger, is imperative. Second, the use of volume-controlled ventilation helps to keep short inspiratory times. Peak airway pressures may increase, but the preserved expiratory time guarantees low auto-PEEP and, consequently, low plateau pressures. For safety, plateau pressures and autoPEEP should be measured periodically. Third, in selected cases with high recruitability, the alveolar dead space can be minimized through recruitment maneuvers and higher PEEP values. Finally, the use of a short endinspiratory pause is encouraged to improve the $\mathrm{CO}_{2}$ elimination [9]. These measures will improve the safety and optimize the $\mathrm{CO}_{2}$ elimination of a strategy with very low tidal volumes, even with higher-than-normal respiratory rates.

However, even successfully avoiding $\mathrm{CO}_{2}$ retention, this strategy has yet to be proven effective in terms of further lung protection. We believe that two aspects should be taken into consideration. The first is whether the strategy attenuated the mechanisms of lung injury. The authors performed computed tomography scans in all patients at tidal volumes of both 4 and $6 \mathrm{~mL} / \mathrm{kg}$ and showed that the amount of cyclic recruitment-derecruitment and hyperinflation decreased after reducing the tidal volume. Although the absolute reduction was small (less than $1 \%$ 
of the lung weight), this finding is suggestive of decreased injury per breath. The second aspect is that an increased respiratory rate can be injurious per se [10]. It would be important to know whether the compensatory increase of the respiratory rate blunted the protective effect per breath of the tidal volume reduction.

This tradeoff was emphasized recently in a model of the energy delivered by the ventilator as a surrogate for the potential lung damage [11]. Decreases in tidal volume require disproportionate increases in respiratory rate to maintain alveolar ventilation, and so more energy can be delivered to the lungs even at reduced stress and strain per breath. Though purely theoretical, this hypothesis helps reconcile our expectation of a further protective effect of very low tidal volumes with the recent findings of harmful or null effect of oscillatory high-frequency ventilation [5,6]. In these trials, it is possible that the reduction in lung injury per breath was offset by the very high respiratory rates applied.

Finally, Retamal and colleagues [1] followed their patients for 5 to 30 minutes only. Since lower tidal volumes tend to promote atelectasis, especially under insufficient PEEP [12], a longer observation time perhaps would have shown an increase in atelectasis and driving pressures, opposing the benefits initially achieved.

In conclusion, we are convinced that a strategy with very low tidal volumes $(4 \mathrm{~mL} / \mathrm{kg})$ is feasible with conventional positive-pressure ventilation. This strategy could be used in patients with high plateau pressures or high driving pressures with standard $6 \mathrm{~mL} / \mathrm{kg}$ tidal volumes, but we need more data in terms of lung protection before we can recommend this strategy to every patient with ARDS.

\section{Abbreviations}

ARDS, acute respiratory distress syndrome; auto-PEEP, auto-positive endexpiratory pressure; $\mathrm{CO}_{2}$, carbon dioxide.

\section{Competing interests}

EC declares that he has no competing interests. MA reports that his research laboratory received grants from Newport Medical Instruments (Costa Mesa, (A, USA) in 2012 and that he has received consulting fees from Covidien (Mansfield, MA, USA); the grants and the fees were related to performance evaluations of mechanical ventilators. He has also received research grants from Dixtal/Philips (Eindhoven, The Netherlands) which are related to the development of electrical impedance tomography.

\section{Acknowledgments}

This study was partially supported by FAPESP (Fundação de Amparo e Pesquisa do Estado de São Paulo) and CNPQ (Conselho Nacional de Pesquisa e Desenvolvimento).

\section{Author details}

'Cardio-Pulmonary Department, Pulmonary Division, Hospital das Clínicas, University of São Paulo, Av. Dr. Arnaldo 455, sala 2144 (2nd floor), São Paulo, SP, Brazil. CEP: 01246-903. 'Research and Education Institute of Hospital Sírio Libanês in São Paulo, R Cel Nicolau dos Santos, 69, São Paulo, Brazil. CEP: 01308-60

Published: 28 March 2013

\section{References}

1. Retamal J, Libuy J, Jimenez M, Delgado M, Besa C, Bugedo G, Bruhn A: Preliminary study of ventilation with $4 \mathrm{ml} / \mathrm{kg}$ tidal volume in acute respiratory distress syndrome: feasibility and effects on cyclic recruitment - derecruitment and hyperinflation. Crit Care 2013, 17:R16.

2. Frank JA, Gutierrez JA, Jones KD, Allen L, Dobbs L, Matthay MA: Low tidal volume reduces epithelial and endothelial injury in acid-injured rat lungs. Am J Respir Crit Care Med 2002, 165:242-249.

3. Needham DM, Colantuoni E, Mendez-Tellez PA, Dinglas VD, Sevransky JE, Dennison Himmelfarb CR, Desai SV, Shanholtz C, Brower RG, Pronovost PJ: Lung protective mechanical ventilation and two year survival in patients with acute lung injury: prospective cohort study. BMJ 2012, 344:e2124.

4. Morris AH, Wallace CJ, Menlove RL, Clemmer TP, Orme JF Jr, Weaver LK, Dean NC, Thomas F, East TD, Pace NL, Suchyta MR, Beck E, Bombino M, Sittig DF, Böhm S, Hoffmann B, Becks H, Butler S, Pearl J, Rasmusson B: Randomized clinical trial of pressure-controlled inverse ratio ventilation and extracorporeal $\mathrm{CO} 2$ removal for adult respiratory distress syndrome. Am J Respir Crit Care Med 1994, 149 (2 Pt 1):295-305.

5. Ferguson ND, Cook DJ, Guyatt GH, Mehta S, Hand L, Austin P, Zhou Q, Matte A, Walter SD, Lamontagne F, Granton JT, Arabi YM, Arroliga AC, Stewart TE, Slutsky AS, Meade MO; OSCILLATE Trial Investigators; Canadian Critical Care Trials Group: High-frequency oscillation in early acute respiratory distress syndrome. N Eng/ J Med 2013, 368:795-805.

6. Young D, Lamb SE, Shah S, MacKenzie I, Tunnicliffe W, Lall R, Rowan K, Cuthbertson BH: High-frequency oscillation for acute respiratory distress syndrome. N Engl J Med 2013, 368:806-813.

7. Nuckton TJ, Alonso JA, Kallet RH, Daniel BM, Pittet JF, Eisner MD, Matthay MA: Pulmonary dead-space fraction as a risk factor for death in the acute respiratory distress syndrome. N Eng/ J Med 2002, 346:1281-1286.

8. Costa $E L$, Amato MB: The new definition for acute lung injury and acute respiratory distress syndrome: is there room for improvement? Curr Opin Crit Care 2013, 19:16-23.

9. Aboab J, Niklason L, Uttman L, Kouatchet A, Brochard L, Jonson B: CO2 elimination at varying inspiratory pause in acute lung injury. Clin Physiol Funct Imaging 2007, 27:2-6.

10. Mascheroni D, Kolobow T, Fumagalli R, Moretti MP, Chen V, Buckhold D: Acute respiratory failure following pharmacologically induced hyperventilation: an experimental animal study. Intensive Care Med 1988, 15:8-14.

11. Brunner JX, Wysocki M: Is there an optimal breath pattern to minimize stress and strain during mechanical ventilation? Intensive Care Med 2009, 35:1479-1483.

12. Muscedere JG, Mullen JB, Gan K, Slutsky AS: Tidal ventilation at low airway pressures can augment lung injury. Am J Respir Crit Care Med 1994, 149:1327-1334. doi:10.1186/cc12556

Cite this article as: Costa ELV, Amato MBP: Ultra-protective tidal volume: how low should we go? Critical Care 2013, 17:127. 